\title{
Pendampingan Pengolahan dan Pengemasan Tanaman Obat Keluarga di Dusun Kemesu Kulon Progo Daerah Istimewa Yogyakarta
}

\author{
Assistance in Processing and Packaging of Family Medicinal Plants in Kemesu Kulon Progo, \\ Yogyakarta Special Region
}

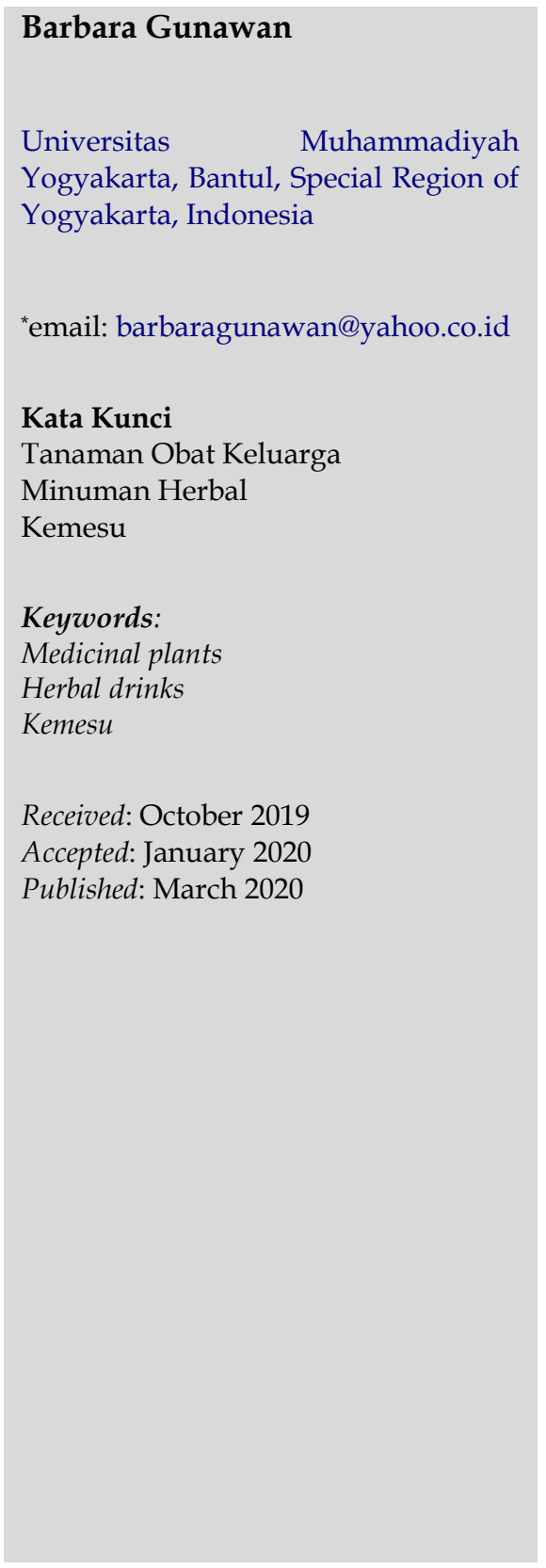

\begin{abstract}
Abstrak
Tujuan pengabdian ini adalah memberikan pelatihan dan pendampingan tentang pengolahan dan pengemasan tanaman obat untuk mengembangkan masyarakat yang mandiri secara ekonomi. Mitra usaha dalam program ini Ibu-ibu PKK Dusun Kemesu Kabupaten Kulon Progo Daerah Istimewa Yogyakarta. Permasalahan yang dihadapi oleh Mitra adalah minimnya pengetahuan tentang cara pengolahan tanaman obat agar bernilai tambah dan dapat dijual sehingga bisa menambah penghasilan bagi keluarga. Metode yang dipakai untuk menyelesaikan masalah adalah dengan 1) Memberikan penyuluhan tentang pemanfaatan tanaman obat, 2) Memberi pelatihan pembuatan produk wedang herbal celup, 3) Memberi pelatihan dan pendampingan cara pengemasan produk wedang herbal celup, dan memberi pelatihan serta pendampingan tentang cara pemasaran produk wedang herbal celup Metode yang digunakan untuk mengimplementasikan pengabdian ini adalah dengan memberikan edukasi mengenai manfaat tanaman obat keluarga dan pelatihan pembuatan minuman herbal. Hasil akhir menunjukkan adanya peningkatan pengetahuan setelah diberikan edukasi maupun pelatihan yaitu pembuatan produk herbal celup hingga dikemas dan bermerk, pemasaran produk, mendapatkan PIRT dari Dinas Kesehatan Kabupaten Kulon Progo, serta tercetak dan terdistribusi Buku Panduan Tanaman Obat Keluarga.
\end{abstract}

\begin{abstract}
The purpose of this service is to provide training and assistance on the processing and packaging of medicinal plants to develop an economically independent community. Business partners in this program Family Welfare Movement, Kemesu village, Kulon Progo Regency, Special Region of Yogyakarta. The problem faced by a partner is the lack of knowledge about how to process medicinal plants so that they can be of added value and can be sold so that they can increase income for the family. The method used to solve the problem is by Providing counseling about the use of medicinal plants, Providing training in the manufacture of herbal drink bag product, Providing training and assistance on how to pack herbal drink bag product, and providing training and assistance on how to marketing herbal drink bag product. The final results showed an increase in knowledge after being given education and training, namely the manufacture of herbal products to be packaged and branded, product marketing, obtaining PIRT from the Health Office of the Kulon Progo Regency until printed and distributed by the Family Medicinal Plant Guidebook.
\end{abstract} (http://creativecommons.org/licenses/by-sa/4.0/). DOI: https://doi.org/10.33084/pengabdianmu.v5i2.1047

\section{PENDAHULUAN}

Desa Pagerharjo merupakan salah satu desa yang berada di Kecamatan Samigaluh, Kabupaten Kulon Progo. Desa
Pagerharjo berjarak $6 \mathrm{~km}$ dari Kantor Kecamatan Samigaluh. Pedusunan yang ada di Desa Pagerharjo diantaranya adalah Kalinongko, Jetis, Suren, Beteng, 
Mendolo, Separang, Sarigono, Ngemplak, Plono Barat, Plono Timur, Kemesu, Ngentak, Sinogo, Kalirejo Utara, Kalirejo Selatan, Nglinggo Barat, Nglinggo Timur, Jobolawang, Ngaglik, dan Gegerbajing. Desa Pagerharjo memiliki batas wilayah di sebelah barat Kabupaten Purworejo, sebelah Timur Desa Ngargosari, sebelah utara Kabupaten Purworejo dan Kabupaten Magelang, dan sebelah selatan Desa Banjarsari dan Kabupaten Purworejo. Kemesu merupakan salah satu dusun yang berada di wilayah administratif Desa Pagerharjo. Secara geografis, Dusun Kemesu berada di wilayah dengan suhu dingin, sehingga warga desa banyak yang menanam obat-obatan keluarga seperti jahe, cengkeh, kunyit, serai, dan sebagainya. Permasalahan yang ditemukan di Dusun Kemesu adalah pengolahan tanaman obat keluarga belum optimal, sehingga, pendampingan pengolahan hasil tanaman obat keluarga perlu dioptimalkan.

Tanaman obat keluarga (TOGA) pada hakekatnya adalah tanaman berkhasiat yang biasanya ditanam di lahan pekarangan dan dikelola oleh segenap anggota keluarga (Utami et al., 2018). Tanaman obat biasanya ditanam untuk memenuhi keperluan keluarga akan obat-obatan tradisional yang dapat dibuat sendiri serta aman, karena tidak mengandung bahan kimia, murah, dan mudah diperoleh (Aseptianova, 2019). Penyediaan tanaman obat ini berfungsi sebagai obat herbal di pekarangan sangat membantu keluarga mengatasi permasalahan kesehatan. Qamariah et al. (2019) menyatakan bahwa World Health Organization (WHO) telah merekomendasi penggunaan obat tradisional termasuk obat herbal dalam menjaga kesehatan masyarakat, pencegahan dan pengobatan berbagai penyakit, terutama penyakit kronis, penyakit degeneratif, hingga kanker.

Tanaman TOGA dapat dimanfaatkan untuk pembuatan wedang herbal yang memiliki banyak khasiat untuk
Kesehatan (Sari et al., 2015). Bahan utama wedang herbal adalah rempah-rempah yang diperoleh dari lingkungan setempat antara lain jahe, kapulaga, daun cengkeh, daun pala, sereh, secang, dan cengkeh (Supriani, 2019; Aslamiah et al., 2017). Diharapkan kegiatan pendampingan ini juga akan berdampak pada peningkatan penghasilan di wilayah Dusun Kemesu. Kegiatan yang dilaksanakan yaitu 1) Penyuluhan tentang pemanfaatan tanaman obat, 2) Pelatihan pembuatan produk wedang uwuh, 3) Pengemasan produk wedang uwuh, 4) Pemasaran produk wedang uwuh, serta pembuatan PIRT.

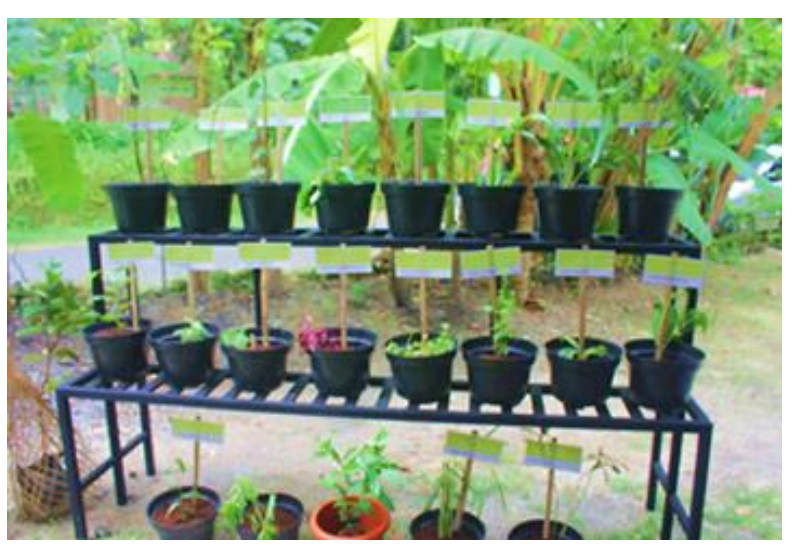

Gambar 1. Tanaman Obat Keluarga.

Tujuan dari program ini adalah mengedukasi dan mendampingi masyarakat agar dapat memanfaatkan potensi hasil sumber daya alam yaitu tanaman obat keluarga yang tersedia di Dusun Kemesu. Pelatihan dan pendampingan diberikan hingga pengemasan dan pemasaran, sehingga dapat meningkatkan pendapatan masyarakat sekitar melalui penjualan produk pengolahan tanaman obat Keluarga (Febriansah, 2017; Nurdiwaty et al., 2017). Hasil penelitian Choironi et al. (2019) menunjukkan bahwa pengetahuan dan keterampilan ibu-ibu PKK di Desa Ketenger Kawasan Wisata Baturraden dalam pengolahan TOGA meningkat

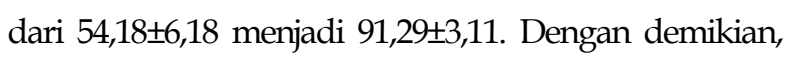
terdapat peningkatan pengetahuan sebesar $41,75 \%$ setelah pelatihan. 


\section{METODOLOGI}

Metode Pengabdian yang dilaksanakan dibagi menjadi

Beberapa tahapan, diantaranya:

1. Focus discussion group tentang produk yang akan dibuat

2. Melakukan penyuluhan tentang pemanfaatan tanaman obat Keluarga.

Mengubah kesadaran, pola pikir dan gaya hidup masyarakat memerlukan adanya penyuluhan. Pemerintah melalui kementerian kesehatan secara terus-menerus melakukan sosialisasi TOGA dan memotivasi masyarakat agar menanam tanaman obat-obatan. Program sosialisasi ini merupakan salah satu tugas Tim Penggerak Pembina Kesejahteraan Keluarga (PKK) yang ada di setiap daerah. Bekerja sama dengan Dinas Kesehatan dan Pembina Kesejahteraan Keluarga (PKK) di masing-masing kabupaten di Indonesia, sosialisasi TOGA terus dilakukan baik melalui pelatihan hingga pengadaan lomba. Namun dalam penyampaian sosialisasi juga diperlukan strategi yang tepat dalam penyampaian. Strategi komunikasi adalah metode atau langkahlangkah yang diambil untuk keberhasilan proses penyampaian pesan oleh seseorang kepada orang lain untuk memberitahu atau mengubah sikap, pendapat dan perilaku, baik secara langsung maupun tidak langsung (Susanto, 2017).

Penyuluhan ini bekerjasama dengan kelompok PKK di Dusun Kemesu dengan tjuan untuk memberikan informasi kepada warga, terkait dengan manfaat TOGA dan cara pemanfaatan tanaman tersebut dengan benar, sehingga masyarakat mampu memanfaatkan tanaman yang sudah tersedia dengan optimal.

3. Pelatihan pembuatan produk wedang uwuh

Dalam pertemuan ini dijelaskan mengenai cara pembuatan wedang herbal, berupa wedang uwuh dalam bentuk instan, yaitu berbentuk serbuk dan dikemas dalam bentuk celup. Pengolahan wedang uwuh dilakukan dengan membuat wedang uwuh dalam bentuk bubuk instan dengan menggunakan peralatan rumah tangga. Bahan utama wedang uwuh merupakah rempah-rempah yang diperoleh dari lingkungan setermpat antara lain jahe, kayu manis, secang, dan dan ranting cengkeh dan daun pala. Kegiatan ini juga dibantu oleh narasumber yang ahli dalam pembuatan wedang herbal tersebut. Tujuan dari kegiatan ini adalah selain memberikan informasi kepada warga terkait dengan cara pembuatan wedang uwuh celup juga dapat memberikan gambaran kepada warga bahwa TOGA bisa diolah menjadi produk yang mempunyai nilai ekonomi yang lebih tinggi apabila dibandingkan dengan penjualan tanaman obat tersebut dalam bentuk mentah atau belum diolah. Sasaran dari kegiatan ini adalah warga dan pemuda sekitar, terutama Kelompok PKK di Dusun Kemesu.

4. Penyuluhan dan pelatihan tentang cara pengemasan dan pemasaran produk wedang uwuh

Dalam kegiatan dijelaskan tentang cara pengemasan yang menarik dan cara pemasaran. Tujuan dari kegiatan ini adalah untuk memberikan pelatihan terkait cara pengemasan yang menarik sehingga masyarakat diharapkan dapat membuat kemasan yang menarik secara mandiri. Selain menjelaskan hal tersebut, dijelaskan juga tentang cara pemasaran produk wedang uwuh, pemasaran dapat dilakukan melalui beberapa cara seperti menggunakan sosial media sebagai wadah promosi, atau memanfaatkan pameran yang sering diselenggarakan di balai desa Pagerharjo atau kantor Kecamatan Samigaluh.

5. Melakukan pendampingan untuk mendapatkan nomor registrasi PIRT di Dinas Kesehatan Kulonprogo 
Pendampingan dilakukan kepada masyarakat untuk mendapatkan informasi sekaligus nomor registrasi PIRT (Produk Industri Rumah Tangga) untuk produk Wedang Herbal yang di hasilkan.

\section{HASIL DAN PEMBAHASAN}

Dusun Kemesu merupakan salah satu dusun yang berada di wilayah administratif Desa Pagerharjo. Secara geografis, Dusun Kemesu berada di wilayah dengan suhu dingin, sehingga warga banyak melakukan penanaman obat-obatan keluarga seperti jahe, cengkeh, kapulaga dan sebagainya. Tanaman obat keluarga di Dusun Kemesu sangat melimpah, namun sebagian besar masyarakat di Dusun Kemesu belum mengetahui cara pengolahan tanaman obat keluarga menjadi sebuah produk yang mempunyai nilai ekonomi lebih tinggi. Untuk meningkatkan nilai ekonomi tersebut, diperlukan pendampingan pengolahan tanaman obat keluarga menjadi sebuah produk yang bernilai jual tinggi.

Pemanfaatan potensi tanaman obat keluarga (TOGA) di Dusun Kemesu kurang maksimal, hal ini dapat dilihat dari banyaknya hasil tanaman obat yang tidak digunakan, dijual mentah tanpa diolah atau tanpa diberi nilai tambah terlebih dahulu. Produk tersebut adalah Wedang Celup Herbal Kemesu. Adapun kegiatan yang telah dilaksanakan yaitu:

1. Penyuluhan tentang pemanfaatan tanaman obat

2. Pelatihan pembuatan produk wedang herbal celup.

3. Pengemasan produk wedang herbal celup

4. Pemasaran produk wedang herbal celup, dan

5. Pembuatan PIRT

Sebelum dilaksanakannya pelatihan tentang pembuatan produk, terlebih dahulu diberikan penyuluhan mengenai manfaat dari tanaman obat keluarga yang ada di sekitar masyarakat. Tujuan dari penyuluhan ini agar masyarakat Dusun Kemesu mampu mengetahui dan memanfaatkan dengan tepat TOGA yang ada di sekitar.
Kegiatan penyuluhan tentang pemanfaatan TOGA

Pada kegiatan penyuluhan, diundang narasumber yang ahli di bidang kefarmasian yaitu Bapak Andhika yang berasal dari Islamic Research Pharmacy Club, Fakultas Kedokteran dan Ilmu Kesehatan Universitas Muhammadiyah Yogyakarta. Pada kegiatan ini narasumber bertugas untuk menjelaskan materi mengenai pemanfaatan tanaman obat keluarga yang ada di lingkungan sekitar. Dalam penyuluhan ini, narasumber menjelaskan mengenai jenis-jenis tanaman obat keluarga, serta manfaat dari tanaman tersebut. Selain itu, narasumber juga menjelaskan kepada masyarakat cara menggunakan tanaman obat dengan tepat dan efek samping dari penggunaan tanaman obat tersebut. Peserta yang hadir pada saat penyuluhan mayoritas berasal dari kelompok Ibu PKK Dusun Kemesu. Masyarakat yang hadir pada saat penyuluhan masih banyak yang belum mengetahui cara penggunaan tanaman obat yang ada disekitar mereka, sehingga pada saat sesi tanya jawab, banyak peserta penyuluhan yang bertanya kepada narasumber. Antusiasme masyarakat dan keingintahuan peserta yang hadir untuk mengetahui manfaat dan cara pemanfaatan TOGA sangat tinggi. Setelah kegiatan penyuluhan ini dilakukan kemudian dibagikan beberapa buku kepada masyarakat Dusun Kemesu untuk menjadi referensi mengenai TOGA dan pemanfaatannya.

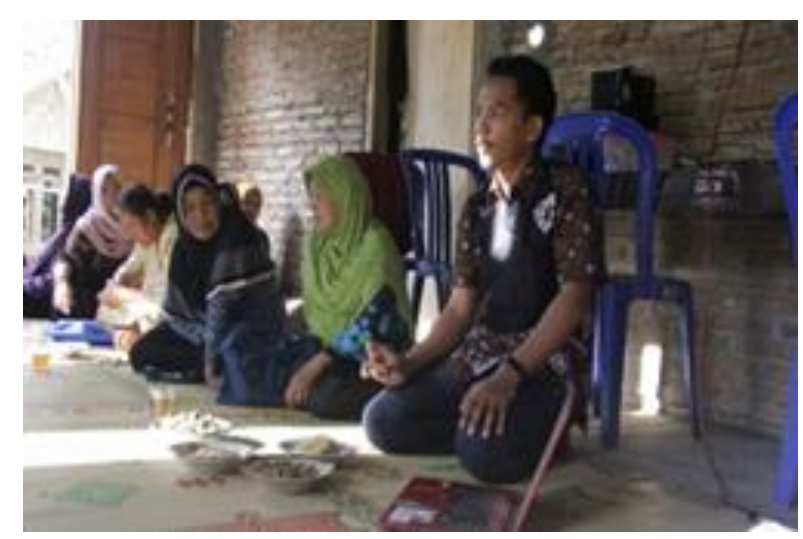

Gambar 2. Penyuluhan Manfaat TOGA. 


\section{Pelatihan pembuatan produk}

Kegiatan pelatihan pembuatan produk dihadiri oleh Kelompok Ibu PKK Dusun Kemesu. Dalam kegiatan ini, pengabdi mengundang narasumber yaitu Bapak Catur Pambudi yang sudah berhasil membuat produk wedang uwuh. Produk yang pengabdi fokuskan adalah wedang uwuh dalam bentuk celup. Alat dan bahan sangat mudah ditemukan, sehingga masyarakat bisa mengikuti dan mengembangkan produk tersebut. Pada saat pelatihan, narasumber menjelaskan mengenai cara pembuatan produk yang benar, sedangkan pengabdi mempraktikkan pembuatan produk tersebut, sehingga masyarakat bisa mendapatkan gambaran secara jelas mengenai pembuatan produk tersebut. Pada saat proses pelatihan selesai, produk yang dihasilkan dibagikan kepada masyarakat.

Berikut adalah cara pembuatan produk:

\section{Bahan:}

1. Jahe 150 gram

2. Kapulaga 100 gram

3. Daun Cengkeh 100 gram

4. Daun Pala 100 gram

5. Sereh 40 gram

6. Secang 100 gram

7. Cengkeh 10 gram

\section{Alat:}

1. Wadah untuk menjemur

2. Kain hitam

3. Blender

4. Tea Bag

5. Kemasan

6. Sealer plastik

7. Timbangan

Proses:

1. Jemur bahan dibawah sinar matahari dengan ditutup kain berwarna hitam

2. Apabila sudah kering, haluskan bahan
3. Campur bahan yang sudah dihaluskan sesuai dengan takaran kedalam wadah

4. Masukkan 5 gram bahan yang sudah dihaluskan kedalam tea bag

5. Masukkan 12 tea bag berisi kedalam satu kemasan

Manfaat Wedang Celup Herbal Kemesu sebagai berikut:

1. Mencegah timbulnya penyakit kronis seperti kanker, jantung koroner, hipertensi, dan diabetes.

Kandungan kayu secang yang ada di dalam produk dapat berkhasiat sebagai anti oksidan kuat yang dapat meredam bahaya radikal bebas yang dapat menyebabkan timbulnya penyakit-penyakit kronis tersebut.

2. Memperbaiki pencernaan dan menghangatkan badan.

Jahe adalah salah satu bahan yang digunakan untuk membuat produk. Jahe berfungsi untuk memperbaiki pencernaan dan menghangatkan badan, hal ini disebabkan oleh kandungan oleoresin pada jahe yang dapat merangsang selaput lender perut besar pada usus.

3. Menghilangkan rasa mual atau mabuk berkendara.

4. Mengatasi masuk angin.

Kandungan cengkeh yang terdapat dalam produk dapat mengatasi masuk angin karena sifat kimiawi dan efek farmakologis dari cengkeh adalah hangat, rasanya tajam, berkhasiat sebagai stimulan, menghilangkan kolik.

5. Obat batuk.

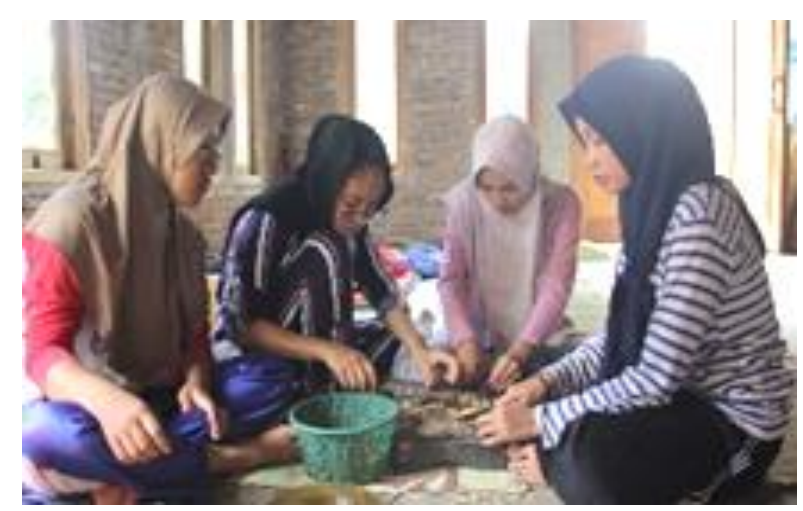

Gambar 3. Pembuatan dan Peracikan Produk. 


\section{Pengemasan dan pemasaran produk}

Kegiatan pengemasan dilakukan setelah kegiatan pelatihan pembuatan produk, pada saat pelatihan proses pengemasan, pengabdi memberikan contoh kemasan dan label merek. Setelah proses pengemasan, kegiatan selanjutnya adalah cara pemasaran produk. Dalam kegiatan pelatihan pemasaran, banyak ide dari peserta untuk memberikan merek atau brand produk, beberapa diantaranya adalah wedang rempah merah Kemesu, wedang herbal Kemesu. Namun, kemasan dan merek yang pengabdi tawarkan adalah Wedang Celup Herbal Kemesu. Setelah kegiatan ini dilaksanakan, masyarakat diharapkan dapat melanjutkan dan mengembangkan produksi produk sehingga dapat meningkatkan perekonomian di Dusun Kemesu.

Dalam pelatihan ini metode yang pengabdi terapkan yaitu narasumber menjelaskan tentang bagaimana cara membuat produk dengan benar, seperti cara menjemur bahan dengan benar agar tidak merusak zat yang terkandung didalam wedang herbal. Pada saat narasumber menjelaskan cara pembuatan produk, pengabdi pengabdi mendemonstrasikan cara pembuatan Wedang Celup Herbal Kemesu. Demi tercapainya keberlanjutan terhadap produksi Wedang Celup Herbal Kemesu. Maka diperlukan rencana tindak lanjut untuk produk Wedang Celup Herbal Kemesu.

\section{Pendampingan Pengajuan P-IRT}

Pengajuan P-IRT membutuhkan waktu yang cukup lama karena menunggu jadwal panggilan pelatihan yang merupakan regulasi dari Dinas Kesehatan, sedangkan dalam periode pengabdian kali ini hanya bisa melakukan pendampingan mulai tahap pencarian informasi syarat-syarat pengajuan P-IRT serta pendaftaran P-IRT dan masih banyak tahap-tahap pengajuan P-IRT yang belum terlaksana seperti pelatihan, pengecekkan air serta pengecekkan proses produksi dan tahap lainnya.

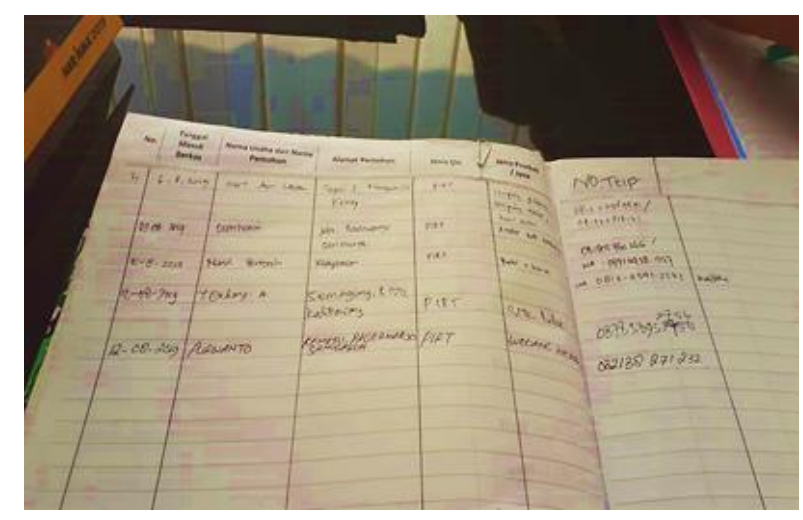

Gambar 4. Pendaftaran PIRT di Dinas Kesehatan Kulonprogo.

Menjadikan "Wedang Celup Herbal Kemesu" sebagai produk unggulan Dusun Kemesu

Dengan potensi tanaman obat keluarga yang melimpah, Dusun Kemesu dapat mengolah potensi tersebut menjadi produk yang dapat meningkatkan perekonomian warga Kemesu. Wedang Celup Herbal Kemesu dapat dijadikan sebagai produk unggulan Dusun Kemesu, produk ini dapat dilanjutkan dan dikembangkan oleh warga Kemesu. Pengabdi telah mengajak beberapa orang warga menjadi sebuah kelompok yang akan mengembangkan dan melanjutkan produk Wedang Celup Herbal Kemesu. Kelompok ini juga yang akan melanjutkan dan mengembangkan produksi Wedang Celup Herbal Kemesu, dimulai dari mempersiapkan tempat produksi hingga mendapatkan izin produksi dari Dinas Kesehatan.

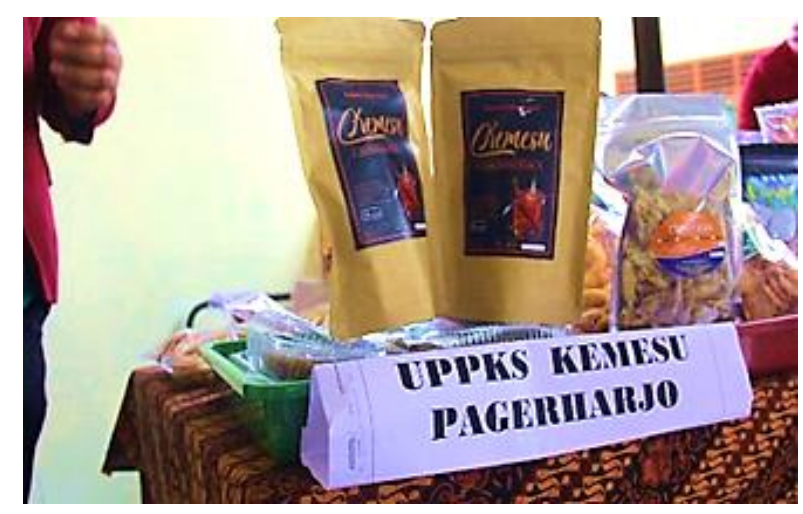

Gambar 5. Produk Wedang Celup Herbal Kemesu. 
Kaderisasi untuk keberlanjutan produk "Wedang Celup Herbal Kemesu"

Untuk memastikan keberlanjutan dari produk ini, pengabdi telah mendatangi dan mengajak beberapa warga untuk menjadi kelompok yang akan mengembangkan produksi “Wedang Celup Herbal Kemesu". Berikut adalah susunan kelompok tersebut:

1. Penanggung Jawab : Purwanto

2. Penggerak Ibu PKK : Ibu Yuli

3. Penanggungjawab produksi : Ibu Sugi

Tercetak dan terdistribusi Buku Panduan Tanaman Obat Keluarga

Upaya promotif melalui media cetak agar dengan mudah dapat diterima masyarakat. Buku tersebut dapat digunakan sebagai panduan keluarga untuk membudidayakan tanaman obat secara mandiri dan memanfaatkannya. Sehingga akan terwujud prinsip kemandirian dalam pengobatan keluarga.

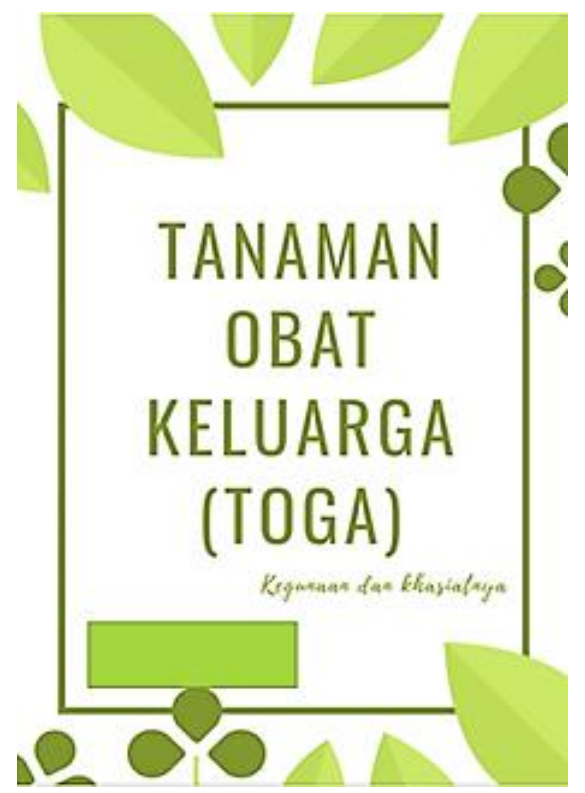

Gambar 6. Buku Panduan Tanaman Obat Keluarga.

\section{KESIMPULAN}

Kegiatan pemberdayaan pada kelompok PKK Dusun Kemesu, telah berjalan dengan baik, meliputi kegiatan pelatihan pengenalan tanaman obat, praktik pengolahan tanaman obat menjadi sediaan wedang herbal. Melalui kegiatan ini telah terjadi peningkatan pengetahuan warga terhadap jenis-jenis tanaman obat dan meningkatkan jumlah koleksi tanaman obat yang dimiliki. Produk Wedang Celup Herbal Kemesu adalah produk yang dihasilkan dari program pelatihan pemanfaatan tanaman obat keluarga menjadi produk yang bernilai ekonomi. Produk ini diharapkan dapat dijadikan sebagai salah satu produk unggulan Dusun Kemesu. Hasil tanaman obat keluarga di Dusun Kemesu sangat melimpah, namun masyarakat belum mampu memanfaatkan potensi tersebut secara optimal. Salah satu cara untuk mengoptimalkan potensi yang ada adalah dengan mengolah tanaman obat menjadi sebuah produk olahan. Produk "Wedang Celup Herbal Kemesu" dapat dilanjutkan dan dikembangkan oleh masyarakat Dusun Kemesu untuk membantu meningkatkan perekonomian warga Dusun Kemesu. Masyarakat Dusun Kemesu diharapkan dapat melanjutkan dan mengembangkan produk Wedang Celup Herbal Kemesu. Inovasi produk diperlukan untuk meningkatkan daya saing produk terhadap produk sejenis lainnya. Untuk bisa memasarkan produk, pengabdi telah mengajak beberapa orang warga menjadi sebuah kelompok yang akan mengembangkan dan melanjutkan produk Wedang Celup Herbal Kemesu. Kelompok ini juga yang akan melanjutkan dan mengembangkan produksi Wedang Celup Herbal Kemesu, dimulai dari mempersiapkan tempat produksi hingga mendapatkan izin produksi dari Dinas Kesehatan.

\section{UCAPAN TERIMA KASIH}

Terima kasih disampaikan kepada Universitas Muhammadiyah Yogyakarta atas kerjasamanya dalam pelaksanaan kegiatan pengabdian kepada masyarakat. 


\section{REFERENSI}

Aseptianova, A. 2019. Utilization Of Family Medicine Plants For Treatment Of Families In Kebun Bunga Village Of Sukarami District, Palembang. Batoboh: Jurnal pengabdian Pada Masyarakat. 4(1):1-25. http://dx.doi.org/10.26887/bt.v3i1.680

Aslamiah, S., Afitah, I., Mariaty, M. 2017. Peningkatan Kesehatan Masyarakat melalui Pemberdayaan Wanita dalam Pemanfaatan Lahan Pekarangan dengan Tanaman Obat Keluarga (TOGA). PengabdianMu: Jurnal Imiah Pengabdian kepada Masyarakat. 2(2):111-117. https://doi.org/10.33084/pengabdianmu.v2i 2.63

Choironi, N.A., Wulandari, M., Susilowati, S.S. 2018. Pengaruh edukasi terhadap pemanfaatan dan peningkatan produktivitas tanaman obat keluarga (TOGA) sebagai minuman herbal instan di Desa Ketenger Baturraden. Kartika: Jurnal Ilmiah Farmasi. 6(1):1-5. http://dx.doi.org/10.26874/kjif.v6i1.115

Febriansah, R. 2017. Pemberdayaan Kelompok Tanaman Obat Keluarga Menuju Keluarga Sehat Di Desa Sumberadi, Mlati, Sleman. Berdikari: Jurnal Inovasi dan Penerapan Ipteks. 5(2):80-90.

Nurdiwaty, D., Puspita, E., Kusumaningtyas, D., Winarko, S.P., Tohari, A., Solikah, M., Faisol, F. 2017. Pemberdayaan Wanita Melalui Tanaman Toga Untuk Membantu Meningkatkan Pendapatan Keluarga. Jurnal ABDINUS: Jurnal Pengabdian Nusantara. 1(1):20-27.

https://doi.org/10.29407/ja.v1i1.11724

Qamariah, N., Handayani, R., Novaryatiin, S. 2019. Peningkatan Pengetahuan dan Keterampilan Ibu Rumah Tangga dalam Pengolahan Tanaman Obat Keluarga (TOGA) sebagai Ramuan Obat Tradisional. PengabdianMu: Jurnal Ilmiah Pengabdian kepada Masyarakat. 4(1):50-54.

https://doi.org/10.33084/pengabdianmu.v4i 1.692

Sari, I.D., Yuniar, Y., Siahaan, S., Riswati, Syaripuddin, M. 2015. Tradisi Masyarakat dalam Penanaman dan Pemanfaatan Tumbuhan Obat Lekat di Pekarangan. Jurnal Kefarmasian Indonesia. 5(2):123-132. http://dx.doi.org/10.22435/jki.v5i2.4407.123132

Supriani, A. 2019. Peranan Minuman Dari Ekstrak Jahecang Untuk Meningkatkan Kesehatan Masyarakat. Jurnal SainHealth.3(1):30-39.

Susanto, A. 2017. Komunikasi Dalam Sosialisasi Tanaman Obat Keluarga (TOGA) Di Kecamatan Margadana. Parapemikir: Jurnal Ilmiah Farmasi. 6(1):111-117. http://dx.doi.org/10.30591/pjif.v6i1.476

Utami, F.P., Matahari, R., Ikhsanudin, A. 2018. Pengoptimalan Potensi Alam Desa Melalui Penataan Taman Tanaman Obat Keluarga (TOGA) dan Pengolahan Wedang Uwuh. Jurnal Pengabdian Kepada Masyarakat. 8(2):13-18. http:/ /dx.doi.org/10.30999/jpkm.v8i2.227 